\title{
PERAN KYAI SEBAGAI PEMIMPIN INFORMAL DALAM PERUBAHAN SOSIAL MASYARAKAT DESA PEMATANG KECAMATAN KRAGILAN KABUPATEN SERANG
}

\author{
Ade Millatus Sa'adiyyah ${ }^{1}$, Ibnu Wijaya Kusuma ${ }^{2}$ \\ Universitas Banten Jaya \\ Serang, Indonesia
}

Ade.Millatus@gmail.com¹, ibnuweka89@gmail.com²

\begin{abstract}
This research is titled Peran Kyai sebagai Pemimpin Informal dalam Perubahan Sosial Masyarakat Desa Pematang Kecamatan Kragilan Kabupaten Serang which is based on the social changes in the village community in the midst of the community that is indeed associated with the existence of an informal leader. The purpose of this study is to find out how the role played by the kyai figure as an informal leader can play a role in the social change of the village community. The research method used is descriptive analysis research with a qualitative approach, the data source in this study can be processed by extracting information / information directly from information sources that are considered to be related to this research. The results of this study can find out how the role played by Kyai as an informal leader in social change in rural communities which certainly can be proven from the results of research achievements. The conclusion of this study is the figure of Kyai as an informal leader who is in the middle
\end{abstract}

Keywords: Social Change in Village Communities, Kyai as Informal Leaders.

\section{PENDAHULUAN}

Dalam suatu Negara yang memiliki wilayah beserta batasannya yang didalamnya terdapat sekelompok masyarakat, disana pasti ditemukan atau terdapat pemimpin. Sesuai dengan peran dan fungsinya, pemimpin dapat dibedakan menjadi pimpinan formal dan pimpinan informal. Oleh karenanya kyai, menduduki posisi penting dalam konteks masyarakat islam pedesaan. Ia mengambil tempat dan peran sebagai inti proses hubungan antara ummat dengan Tuhan dan masyarakat islam pedesaan dengan dunia luar.
Kepemimpinan muncul bersama-sama adanya peradaban manusia yaitu sejak zaman nabi-nabi dan nenek moyang manusia yang berkumpul bersama, lalu bekerja bersama-sama untuk mempertahankan eksistensi hidupnya menantang kebuasan binatang dialam sekitarnya. Sejak itulah terjadi kerjasama antar manusia dan ada unsur kepemimpinan. Pada saat itu pribadi yang ditunjuk sebagai pemimpin ialah orangorang yang paling kuat, paling cerdas dan berani. Pemimpin informal juga didasarkan 
atas pengakuan dan kepercayaan masyarakat yang diberikan kepada seseorang. Dengan kata lain pimpinan informal lazimnya diketahui oleh masyarakat ialah salah satunya kyai, yang di sahkan tidak melalui pengangkatan formal

Kyai sebagai pemimpin biasanya menerima tugas dan peran tersebut secara sukarela, sebagai manifestasi dari rasa tanggung jawab dan amanah yang dipikulnya. Sebab pada dasarnya bahwa setiap kita adalah pemimpin dan setiap pemimpin akan dimintakan pertanggung jawab. berdasarkan survey pendahuluan yang dilakukan penulis, terhadap kehidupan masyarakat Desa Pematang Kecamatan Kragilan, secara fenomenologis penulis melihat dan sekaligus tertarik terhadap peran yang dimainkan Kyai, sebagai figure dan tokoh masyarakat. Walaupun kyai, tinggal jauh dipedalaman atau pedesaan, namun mereka sesungguhnya "merupakan bagian dari kelompok ellit dalam struktural sosial, politik dan ekonomi masyarakat.(Zamakhsyari Dhofier, 1982:56). Sebagai suatu kelompok sosial, para kyai memiliki akar pengaruh yang sangat kuat di masyarakat desa model. Hal tersebut sejalan dengan konsepsi tentang arti kewibawaan dan keteladanan. Kedua karakter tersebut yang mampu dipertahankan dan dipegang teguh oleh kyai, sehingga terlihat begitu menyatu dalam pribadinya. Fenomena menarik yang menandai suatu peroses perubahan sosial biasanya ditandai atau dimotori oleh adanya suatu kelompok elit dalam masyarakat, entah itu elit politik, ekonomi, elit agama dan lain sebagainya.

Perubahan sosial berarti sesuatu yang berada dari apa yang terjadi di masa lampau. Dari kebanyakan alasan mengapa orang-orang melawan dan menolak akan adanya perubahan dan dari sisi lain banyak orang juga akan menanti saat-saat perubahan sosial tersebut tiba baik secara lambat (tidak disadari) ataupun cepat (perubahan yang dilakukan secara sengaja). Dari apa yang terjadi pada perubahanperubahan sosial tersebut memasuki dua perspektif baik menghantarkan perubahan sosial tersebut kearah pembangunan, dan menghantarkan perubahan yang berdampak pada pembobrokan masyarakat setempat sehingga akan terjadinya kemerosotan kualitas suatu Negara. Dalam matakuliah pendidikan Karakter Bangsa Deni Surya Permana menyatakan terdapat tiga macam karakter masyarakat:

1. stone citizen (warga batu)

2. sponge citizen (warga busa)

3. generator citizen (warga pembangkit). 
Yang dimaksud dengan stone citizen (warga batu) ialah warga yang keras kepala tidak bisa menerima hal apapun dari eksternal, Selanjutnya sponge citizen (warga busa) warga yang terlalu mudah menyerap apapun dari eksternal, dan yang terakhir generator citizen (warga pembangkit) adalah warga yang dapat menyaring antara baik dan buruknya dari factor eksternal.

Pada kesempatan ini, peneliti telah melakukan prapenelitian. Melalui pengamatan dan beberapa wawancara dengan masyarakat setempat mendapatkan suatu kisah terdahulu bahwa masyarakat Desa Pematang, Kecamatan Kragilan, Kabupaten Serang mengalami beberapa perubahan sosial masyarakat Desa. "Desa Pematang dahulu ada pesantren yang memang besar dengan ratusan santri (tidak menyebutkan tahun) dan di pimpin oleh seseorang kyai besar jebolan dari Makkah yang kebetulan teman seperjuangan dari Syekh Nawawi Caringin (tidak menyebutkan nama), tapi tidak ada yang menggantikan atau meneruskan memimpin pesantren tersebut. Alhasil para santri kocar-kacir berpergian, singkat cerita pesntren tersebut hilang." (Abdul Azizy. Masyarakat setempat). Dari latar belakang masalah di atas, penulis tertarik atas beberapa perubahan sosial masyarakat tersebut. Apakah perubahan sosial masyarakat tersebut atas peran dari kyai sebagai tokoh masyarakat dan sebagai pemimpin informal. Maka penulis menyimpulkan untuk mengambil judul pada penelitian ini sebagai berikut "Peran Kyai Sebagai Pemimpin Informal Dalam Perubahan Sosial Masyarakat Desa Pematang Kecamatan Kragilan”.

\section{METODE PENELITIAN.}

Lokasi penelitian ini berada di Desa Pematang, Kecamatan Kragilan, Kabupaten Serang. waktu penelitian telah di mulai dari bulan bulan Maret 2019 sampai dengan Agustus 2019. Dalam penelitian ini, peneliti menggunakan metode deskriptif, metode deskriptif adalah suatu metode dalam meneliti suatu kelompok manusia, suatu objek, suatu kondisi, suatu tujuan pemikiran, ataupun suatu kelas peristiwa pada masa sekarang. Penelitian deskriptif merupakan penelitian yang berusaha mendeskripsikan dan menginterpresikan sesuatu, misalnya kondisi atau hubungan yang ada, pendapat yang berkembang, proses yang sedang berlangsung, akibat atau efek yang terjadi, atau tentang kecenderungan yang telah berlangsung. penelitian deskriptif adalah penelitian yang dilakukan untuk mengetahui nilai variable mendiri, baik suatu variable atau lebih tanpa membuat perbandingan, atau hubungan dengan variable yang lain. 
(Cooper H.M dalam Sudaryono, 2017:82). Penelitian deskriptif merupakan penelitian yang berusaha mendeskripsikan dan menginterpresikan sesuatu, misalnya kondisi atau hubungan yang ada, pendapat yang berkembang, proses yang sedang berlangsung, akibat atau efek yang terjadi, atau tentang kecenderungan yang telah berlangsung. Prosedur pengumpulan data dalam penelitian ini yaitu Observasi, kegiatan pemusatan perhatian terhadap sesuatu objek penelitian dan menggunakan seluruh alat indera (Suharsimi Arikunto, 2006:234). Penulis melakukan pengamatan secara langsung untuk memperoleh data. Dan teknik wawancara, yaitu wawancara langsung kepada informan yang dituju, dengan mempersiapkan pertanyaan yang telah di rumuskan terlebih dahulu. Data yang dikumpulkan dalam penelitian ini adalah data primer dan data sekunder :

a. Data primer yang dikumpulkan adalah data yang bersifat kualitatif. Selain itu data primer, ialah data yang dapat diperoleh secara langsung oleh peneliti yang berasal dari informan atau sumber data melalui teknik wawancara.

b. Data sekunder yang dikumpulkan berupa data kualitatif yang dapat digunakan peneliti sebagai penunjang atau pendukung data primer.
Data sekunder yaitu data yang didapatkan atau dihasilkan dari dokumen-dokumen tertulis yang berkaitan dengan fokus yang diteliti di Desa Pematang, Kecamatang Kragilan. Analisis data yang digunakan dalam penelitian ini adalah analisis data kualitatif. Menurut Bogdan dan Biklen (dalam Moleong, 2006), bahwa analisis data kualitatif adalah upaya yang dilakukan dengan jalan bekerja dengan data, mengorganisasikan data, memilah-milah data menjadi satuan-satuan yang dapat dikelola, menyintesiskan data, mencari dan menemukan pola-pola, menemukan apa yang penting dan apa yang dipelajari, dan Adapun analisis kualitatif dalam penelitian ini ialah model analisis inter memutuskan apa yang dapat diceritakan kepada orang lain. aktif yang terdiri dari pengumpulan data, penyajian data, dan penarikan kesimpulan atau verifikasi, seperti digambarkan berikut ini : Pengumpulan Data.

Pengumpulan data pada penelitian ini menggunakan teknik wawancara dan mengutamakan pedoman wawancara pada saat malaksanakan penelitian. Reduksi data. Reduksi data ialah proses penelitian yang melalui, pemusatan perhatian pada penyederhanaan, pengabstraksian, dan transformasi hasil data kasar yang muncul saat penelitian berlangsung dari catatancatatan yang didapatkan dilapangan. Penarikan kesimpulan atau verifikasi. 
Penarikan kesimpulan adalah penarikan simpulan atas hasil penelitian yang telah melalui sitematika penelitian sehingga dapat di simpulkan secara deskriptif mendalam agar dapat meluaskan cabang ilmu pengetahuan.

\section{HASIL PENELITIAN DAN PEMBAHASAN}

Sesuai apa yang telah peneliti tentukan pada saat melakukan penelitian, peneliti melakukan wawancara terhadap beberapa informan untuk memperoleh data penelitian di Desa Pematang Kecamatan Kragilan Kabupaten Serang-Banten, peneliti menempuh wawancara dengan beberapa informan yang telah dilakukan oleh peneliti terkait wawancara terhadap kyai serta masyarakat setempat yang memang dipilih karena dianggap memumpuni apa yang diharapkan oleh peneliti. Peneliti dapat menjabarkan apa yang telah di peroleh sebagai berikut:

1. Peran kyai yang dilakukan ditengahtengah masyarakat sebagai motivator. Jadi kyai disini memiliki caranya sebagai motivator yang berada ditengahtengah masyarakat dengan cara mengajak masyarakat kedalam kegiatan yang memang mengenai keagamaan, agar masyarakat memiliki dasar yang memang dapat menjaga keutuhan masyarakat. Maka peran kyai harus dapat membuktikan nya yang dimulai dari diri sendiri yang berbuat mengawali menepati janji dan sebagainya agar masyarakat turut ikut serta apa yang di arahkan oleh kyai dalam segala hal kebaikan keagamaan. Kegiatan yang memang berkenaan atau bersentuhan langsung kepada masyarakat yakni ada beberapa rutinitas kegiatan seperti pengajian rutin yang di selenggarakan pada setiap hari rabu dan jum'at, serta yang diselengarakan perbulanan dan jika diruang lingkup kita terdapat suatu pondok pesantren secara tidak disadari masyarakat memiliki rem nya untuk menahan diri. Kegiatan tersebut bertujuan mempererat tali silaturahmi sesama umat islam dan masyarakat setempat, dengan adanya kegiatan tersebut dapat membekali masyarakat nya dalam bermasyarakat dan dalam berperilaku yang baik. dengan adanya kegiatan tersebut dan ruang lingkup kita terdapat suatu pondok pesantren secara tidak disadari masyarakat memiliki rem untuk menahan diri dalam bertindak yang bertentangan dengan ajaran islam. Peran Kyai yang dilakukan ditengahtengah masyarakat sebagai motivator yaitu sebuah siraman rohani disetiap ada jadwal untuk mengisi acara yang mana tentang keagamaan, karena pada waktu itu lah yang digunakan saya dalam 
menjaga keutuhan agama islam di Indonesia, adapun yang saya lakukan selain itu mengisi pengajian rutin di majelista'lim yang ada di desa Pematang, selain itu kebetulan saya juga memiliki pondok pesantren dan ada kegiatan yang memang saya terjunkan santri untuk berbaur terhadap masyarakat dalam bersosialisasi demi terjaganya ukhuwah islamiyah. Dengan adanya rutinitas pengajian yang memang telah berlangsung dan diberikan waktu untuk berceramah itu lah hal yang memang momen untuk menyebarkan pengetahuan keagamaan.

2. Kyai mengajar kitab-kitab islam klasik. Tidak hanya pada ruang lingkup pesantren mengajarkan kitab-kitab tetapi pada saat pengajaian rutin masyarakat pun turut di bahas karena memang pada masyarakat yang memang hanya memalui penidikan formal tidak ada pembahasan tentang kitab-kitab islam. Mengajarkan kitab-kitab islam klasik dikalangan santri maupun kalangan masyarakat sekitar, karena pengetahuan tentang seluk beluk tata cara beribadah keehidupan bertetangga itu ada di kitabnya seperti yang tak asing lagi yaitu kitab kuning, akan tetapi ada saja masyarakat yang memang hanya tau nama kitab nya saja dan belum tentu mengetahui dan memahami isi dari pembahasannya.
3. Peran yang dilakukan kyai dalam perubahan sosial yang terjadi pada masyarakat. Ragam perubahan ada yang dapat membawa kearah positif ada pula yang ke arah negatif. Perubahanperubahan yang terjadi pada desa Pematang sendiri mengalami berbagai perubahan baik itu secara di sadari atau tidak disadari perubahan tersebut pasti terjadi. Perubahan yang memang sangat dasar adalah gaya kehidupan di jaman sekarang yang memang bermacammacam baik itu terserang dari intern maupun extern, positif maupun negatif. infrastruktur yang ada di desa Pematang karena 13 tahun belakangan ini mulai bermunculan pembangunan perumahan itulah yang terlihat secara kasat mata, dengan ada nya perumahan otomatis besar persentase pendudukuk akan mengalami kenaikan dan otomatis desa Pematang akan ramai tak lagi sepi.

\section{PEMBAHASAN}

Dari rangkaian-rangkaian yang telah peneliti susun untuk menjalankan suatu penelitian yang memang bebas hambatan dan tanpa kawatir kehilangan arah, maka peneliti telah menemukan data-data baik secara data yang telah ada maupun data dari hasil pengamatan dilapangan serta data dari responden yang telah di wawancarai.berikut adalah pembahasannya: 
1. Peran Kyai sebagai Pemimpin Informal dalam Perubahan Sosial Masyarakat Desa Pematang Kecamatan Kragilan .

a. Seorang kyai dalam memberikan motivator terhadap masyarakat itu mampu untak bisa merangkul warganya dalam menjalankan kehidupan yang beragama baik secara individual maupun kelompok, karena kyai memiliki kewibawaan yang baik akan mudah dalam merangkul warga setempat untuk ikut serta dalam kegiatan tersbut, selain itu kyai pula mampu memberikan stimulus agar para santri dapat berperan aktif pada lingkungan masyarakat yang sebenarnya, dalam pemberian motivasi tersbut terdapat menjadi dua macam adayang memang dengan cara verbal, yang langsung di ucapkan oleh kyai untuk ikut serta dalam kegiatan tertentu kepada masyarakat sekitar, dan yang non verbal, mencakup segala ajakan-ajakan yang memang tidak lagi hanya mengandalkan ucapan yang di utarakan oleh seseorang akan tetapi sudah berupa tindakan yang memang mengarahkan dan mencontohkan untuk kita pun berlaku seperti demikian.

b. Selain kyai mengajarkan kitab-kitab yang ada kepada santri-santrinya, kyai pun dalam melaksanakan kegiatan pengajaian rutin yang dilaksanakan pada setiap minggu atau bulan bahkan tahunan pun tetap mengajarkan kita-kitab yang memang sebagai dasar pendamping pedoman dari pada Al-Qur'an

c. Untuk menyikapi hal-hal yang memang akan terjadi pada masyarakat kyai berperan agar masyarakat tetap dalam ruang lingkup keislaman yang baik dan tetap dalam arahan. Dengan demikian masyarakat tak perlu kawatir kembali akan penyimpangan-penyimpangan sosial yang akan terjadi pada suatu saat nanti. Dengan metode pengajian dan ceramah yang memang rutin dilaksanakan demi terjaga nya kerukunan yang telah tercipta sejak dulu di lingkungan desa Pematang ini.

\section{Perubahan Sosial Masyarakat Desa}

Masyarakar desa telah menetukan dan serasa aka nada nya pengakuan bahwa sosok kyai di tengah-tengah masyarakat pun berperan dalam menjalankan kehidupan bermasyarakat, masyarakat desa pun banyak yang taat kepada sosok kyai karena menurut nya kyai merupakan orang yang banyak tah tentang segala hal. Terutama dalam masalah kepemimpimpinan kyai dalam masyarakat. Dalam hal memimpin tak mungkin seorang kyai menjerumuskan 
warganya. Dalam hal ini meskipun peran kyai tak banyak masyarakat menyadarinya akan tetapi kyai memang berperan sebagai pengarah, pengingat dan lain sebagainya yang berkenaan dengan perubahan-perubahan sosial yang ada di kalangan masyarakat.

\section{KESIMPULAN}

Berdasarkan hasil penelitian ini, maka kesimpulann Berdasarkan hasil dari penelitian dan hasil dari pembahasan bab IV peneliti dapat ditarik kesimpulan sebagai berikut :

1. Peran Kyai sebagai Pemimpin Informal dalam Perubahan Sosial Masyarakat Desa Pemtang Kecamatan Kragilan.

Seorang kyai dalam merangkul warga setempat untuk ikut serta dalam kegiatan keagamaan mampu menjadi panutan dan memberikan motivasi, dalam pemberian motivasi tersbut terdapat dua macam cara dengan cara verbal, yang langsung di ucapkan oleh kyai untuk ikut serta dalam kegiatan tertentu kepada masyarakat sekitar, dan yang non verbal, mencakup segala ajakan-ajakan yang memang tidak lagi hanya mengandalkan ucapan yang oleh seseorang akan tetapi sudah berupa tindakan yang memang mengarahkan dan mencontohkan untuk kita pun berlaku seperti demikian. Kyai mengajarkan kitab-kitab islam klasik kepada santri-santrinya, begitu pula dalam melaksanakan kegiatan pengajaian rutin yang dilaksanakan pada setiap minggu atau bulan bahkan tahunan mengajarkan kita-kitab yang memang sebagai dasar pendamping pedoman dari pada Al-Qur'an. Dalam menyikapi hal-hal yang akan terjadi pada masyarakat kyai berperan ditengahtengah masyarakat agar tetap dalam ruang lingkup keislaman yang baik dan tetap dalam aturan yang berlaku dalam keagamaan. Dengan demikian masyarakat tak perlu kawatir akan penyimpangan-penyimpangan sosial yang akan terjadi pada suatu saat nanti. Dengan metode pengajian dan ceramah yang memang rutin dilaksanakan demi terjaga nya kerukunan dalam menjalankan kehidupan bermasyarakat yang telah tercipta sejak dulu di lingkungan desa Pematang ini.

2. Perubahan Sosial Masyarakat Desa. Gelar seorang kyai adalah pemberian dari allah dan di salurkan kepada umatnya yang memang mengakuinya secara langsung akan sosok dari seorang kyai tersebut, masyarakat desa pun taat kepada sosok kyai karena menurut nya kyai merupakan orang yang banyak tahu tentang segala hal. Terutama dalam masalah kepemimpimpinan kyai dalam masyarakat. Dalam hal memimpin tak mungkin seorang kyai menjerumuskan 
warganya. Meskipun peran kyai tak banyak masyarakat menyadarinya akan tetapi kyai memang berperan sebagai pengarah, pengingat dan lain sebagainya yang berkenaan dengan perubahan-perubahan sosial yang ada di kalangan masyarakat.

\section{DAFTAR PUSTAKA}

Sudaryono, (2017) Metode Penelitian (edisi 1), Depok , Rajawali Pres.

Suharsimi Arikunto, (2006), Prosedur Penelitian Suatu Pendekatan Praktek, Jakarta, Rineka Cipta.

Zamakhsyari Dhofier (1982), Tradisi Pesantren, Jakarta, LP3ES. 